\title{
Enhancing segmentation systems
}

Received (in revised form): 7th September, 2008

\section{Henry Greene}

is an assistant professor of marketing at Central Connecticut State University. In addition to his PhD in marketing, he has graduate degrees in mathematics and computer science. He has worked as a marketing research analyst and consultant at Donnelley Marketing, Inc., Strategic Mapping, Inc., ADVO, Inc., Advanced Database Marketing, Young and Rubicam, IBM and Information Xperts. Before his industry experience he served on faculties at Salisbury University, the University of Rhode Island and Indiana University - Malaysia. He has taught courses in mathematics, computer science and statistics. He currently teaches marketing courses, specialising in direct marketing. Henry has also worked as a systems analyst for the US Coast Guard and the Department of the Army.

\begin{abstract}
Shanti Greene
is a senior statistical analyst at Upromise, Inc. in Newton, MA. He holds degrees in computer science and psychology from Case Western Reserve University and the University of Hartford, respectively, and has completed extensive doctoral coursework in marketing at the University of Connecticut. While at the University of Connecticut, Shanti taught marketing management and guest lectured at Central Connecticut State University and the University of Massachusetts. Shanti previously served as president of Information Xperts, LLC, where his experience includes developing geodemographic and household-level segmentation systems, predicting direct marketing responsiveness and modelling customer lifetime value.
\end{abstract}

Keywords segmentation, assessment, geodemography, Gini coefficient, response, exographics

\begin{abstract}
Market segmentation analysis and market segmentation systems, both geodemographic and household-level, have played an important role in marketing strategy, specifically in direct marketing. Geodemographic segmentation has been successfully used in the commercial sector for more than 30 years. During this brief time period, changes have been made to increase the efficiency and effectiveness of these systems. A great deal of emphasis has been directed towards investigating different model types, for example mixed models, clusters, CHAID and CART, with the goal of separating consumers in terms of their heterogeneous purchasing behaviour. The purpose of this paper is to demonstrate how segmentation systems can be enhanced by modifying the systems with additional data dimensions. We propose that generic segmentation systems, built a priori to a general consumer behaviour analysis, can be enhanced by augmenting the systems with data variables known to be correlated with the behaviour of interest, which are not currently utilised in the segmentation system. Three sample files, representing three different industries, are examined. The files are appended with generic segmentation systems and then augmented with exographic variables (data descriptors that represent environmental phenomena beyond one's immediate being and neighborhood). These exographic variables are added to the pool of candidate variables from which the segmentation system is augmented. The results obtained in this study indicate that the proposed strategy of incorporating relevant data with current segmentation systems has potential value with respect to increasing separation between segments with regard to a consumer behaviour of interest. The Gini coefficient is described in this paper as a useful method for assessing segmentation system performance Journal of Targeting, Measurement and Analysis for Marketing (2008) 16, 298-311. doi:10.1057/jt.2008.22
\end{abstract}

\footnotetext{
Correspondence: Henry Greene,

Central Connecticut State University,

1615 Stanley Street, New Britain, CT06050.

Tel: +1 860832 3308;

Fax: +1 860832 3319;

E-mail: Greenehej@CCSU.EDU
}

\section{INTRODUCTION}

Historically, geodemographic segmentation systems were created using Census data as the primary data source for describing residential geographic units. ${ }^{1-5}$ The major advantage of 
Census data is that it offers national aggregate data with complete geographic coverage and is available at a variety of geographic levels. In the United States, Census data are available at the state, county, tract, block group and block level. A more recent development by some of the direct marketing list compiler companies is to create demographic segmentation systems at the household level. This is possible when the list compiler has an assortment of data variables for every household on their file. Several companies have created such systems, for example DNA Metromail Inc. (DNA), Polk Company (Niches), Looking Glass, Inc. (Cohorts II), Acxion, Inc. (Personix) and Claritas (Connexions). Typically, these companies have access to national databases that contain both household demographics (income, age of head of household, length of residence, etc) as well as behavioural characteristics (number of credit lines open, credit ratings, homeownership, etc) or lifestyle activities (pet owners, foreign travellers, golfers, etc).

Bickert $^{6}$ describes building a household system with demographics and lifestyle characteristics, and notes that segmentation systems should be built based on three concepts: consumer need, buying power and spending pattern. Bass et al. ${ }^{7}$ discuss building segmentation systems with socioeconomic, demographic, personality and purchasing characteristics, and note that incorporating psychological and sociological variables would increase the explained variance of predictive models. They also note that the total explained variance with household segmentation systems is rather weak. In either geodemographic segmentation systems or demographic segmentation systems, the pool of data variables is frequently created from what is available rather than what is theoretically most useful. Thus, segmentation systems are built based on information that is convenient rather than optimal. This paper argues that there are available data sources that are inexpensive, theoretically logical and beneficial in terms of their ability to effectively differentiate consumer groups. In addition, these data variables can be easily incorporated into a geodemographic or household-level segmentation system.
On another note, segmentation system performance is usually evaluated and validated with graphs or tables and without any rigorous statistical methodology. In direct marketing, a few researchers have utilised some form of the Gini coefficient ${ }^{8-15}$ in their assessment of model performance. This paper suggests that the Gini coefficient can also be used to assess segmentation performance.

The remainder of this paper is organised as follows. A discussion of segmentation systems is presented, followed by a discussion of forces that affect consumer behaviour. The use of exographic data is explained in the context of segmentation systems, the methodology used to justify additional data dimensions is presented, the results of three analyses are discussed, and conclusions are formulated. The paper concludes with limitations and opportunities.

\section{THE NATURE OF GEODEMOGRAPHIC AND HOUSEHOLD DEMOGRAPHIC SEGMENTATION SYSTEMS}

Geodemographic segmentations systems were originally created in the 1970s, appearing in England as well as the United States. In the United States, these systems were made possible when the US Census Bureau made demographic tables available to the public in an electronic format. At first, the segmentation systems were built at large-scale geographies such as metropolitan statistical areas and postal zip codes. Over time, there was a desire to reduce the geographic scale to Census tracks, then Census block groups, and later to Census blocks and Postal ZIP +4 areas. Database marketers generally believe that building geodemographic systems in smaller geographic areas will add precision to the methodology and improve model performance. Advances in technology have made it possible to produce segmentation systems with millions of small-scale geographies, such as households. Many list compiler companies have access to a national database of demographic variables that cover a high percentage of households throughout the country and use this to create household-level segmentation systems. Such companies have access 
to demographic characteristics such as age, presence of children and length of residence, and may also have access to buyer behaviour characteristics such as number of credit lines, mail order responsiveness, home ownership and credit rating. One of the advantages of household-level data is that they are updated frequently; parts of these databases are typically updated daily. Two of the disadvantages of household-level segmentation systems are difficulty in augmenting data files with supplemental household-level information and increased complexity constructing thematic maps. Geodemographic segments can be appended to a customer file by matching on the appropriate geography (Census block group, postal carrier route, Census block or Postal ZIP + 4), whereas classifying a customer into a householdlevel segmentation system requires a strong match on both the customer name and address. If the customer represents a new household, for example recently married or divorced with a name change or a recent address change, matching would be likely to fail and there would not be an appropriate segment code assigned to the household. As for thematic maps, geographic units have unique codes; they are easy to colour or shade according to segment analysis. Households do not cover geographical areas, and only represent points on a map. One would have to aggregate a set of households and make a variety of assumptions to actually design a thematic map. If the purpose of the segmentation system is, however, to identify households for a direct marketing advertising campaign, a household segmentation system may be preferable because decisions regarding whether or not to communicate to a unique household can be made on an individual basis.

\section{FORCES THAT AFFECT CONSUMER BEHAVIOUR}

Kotler and Anderson ${ }^{16}$ suggest that there are four different types of influencers that affect consumer decision purchasing behaviour. They refer to these influencers as cultural, social, personal and psychographic. Cultural represents the customs and rituals of a person's homeland, race, ethnicity or religion; social represents the mores and habits of a social group, most influential being the immediate family, but also including extended family and social networks. Personal refers to the unique characteristics of an individual such as physical characteristics (height, weight and health) and demographic characteristics (age, income and education). Psychological refers to the attitudes, opinions and interests of the individual, which might include hobbies, tolerance for risk or need for excitement or variety. Naturally, the psychological aspects of an individual are more difficult to capture or measure for a large database of individuals. Other researchers have presented their own opinions as to which variables types are most useful for segmentation purposes. Goss ${ }^{17}$ mentions the utility of geographic and psychographic, Bikert ${ }^{18}$ mentions demographic and lifestyles and Mitchell ${ }^{19}$ mentions demographics and behavioural data. Miller ${ }^{20}$ suggests demographics and psychographics as useful predictors. Greene and Milne ${ }^{21}$ encourage the use of exographics, large-scale environmental characteristics that represent cultural, sociological, natural geographic and man-made geographic attributes of a region.

\section{JUSTIFICATION FOR EXOGRAPHIC DATA}

Although culture is a term that includes many aspects of societal living, there are other environmental conditions that may be useful to explain consumer behaviour. In this paper, we refer to large-scale, environmental characteristics as exographics. These forces apply to geographic areas larger than what one considers a typical neighborhood. For example, if one wanted to sell golf equipment to consumers through a catalogue, one might assess the golf environment (number of golf courses in the Metropolitan Statistical Area (MSA), number of sunny days above 55 degrees, number of people employed as professional or senior management, percentage of adults who belong to an amateur golf organisation, etc). The geographic area is purposely left unspecified because it may vary depending on the characteristics of interest. In the US, the MSA might be appropriate for describing cost of living, given that everyone living in the 
area is subject to similar retail prices, property taxes and utility charges. On the other hand, weather conditions such as snowfall might extend to geographic areas greater than the MSA and might include several counties or even an entire state. Characteristics such as average commute time might only apply to smaller geographies. People living in the five boroughs of New York might have a very different set of government regulations, transportation expenses and cultural benefits than people living in Newark or Fort Lee, New Jersey. The important concept is that where people live has an impact on their consumption. Whether or not individuals recognise the culture that surrounds their habitat, they are still influenced by their surroundings. You do not have to be a fisherman, sailor or deep-sea diver to be affected by living near the ocean. The lifestyle of beach residents differs from inlanders in terms of available foods and restaurants, clothing, recreational activities and home decorations.

\section{METHODOLOGY}

\section{Data: Online shoppers, magazine subscribers, auto insurance inquiries and buyers}

Three different industry applications are represented in this study. The first is an online shopper file of 10,474 shoppers, sampled from a house file of over 9,000,000 customers. The second file represents a golf magazine subscriber file of 1,024 customers and the third contains 125,146 people who inquired about automobile insurance. The first file is appended with household demographics and a household-level segmentation system of 70 clusters. The second and third files are appended with a geodemographic segmentation system consisting of 24 segments. The geodemographic cluster system is built at the US Postal Carrier Route level (there are approximately 500,000 carrier routes in the US). The segmentation system had been used by a particular auto insurance company for several years; they have empirically observed that response behaviour in urban areas and rural areas are dissimilar. All three files were appended with a file of exographic variables at the MSA level. The exographic data set was created by extracting information from the Places Rated Almanac. ${ }^{22}$ Thirty-three variables were created; a list of the variables is included in Table 1 .

\section{File matching}

After matching the exographic file to the online shopper file, 7,792 records remained, representing online shoppers who live in MSAs. Appending exographics to the magazine subscribers yielded 880 records, and in the case of the automobile insurance responders, 103,007 records were successfully matched.

\section{Segmentation analysis}

Segmentation analysis is used commercially for several purposes: profiling customers, identifying potential marketing targets, identifying locations for billboard placement, estimating trade area potential and selecting communication style, to name a few. The analysis begins with attaching segment codes to individual customer records and then summarising the records by segment code. The summaries can represent customers, dollar spending, units sold, marketing campaign response or other buyer behaviours. Frequently, the individual segments are compared to a national or

Table 1: Exographic variables

\begin{tabular}{llll}
\hline Arts & Education & Number buses & Urbanicity \\
Climate & Golf courses & WhiteCollar & Violent crime \\
Collegetown & HazardousDays & PrecipitationDays & Wateracres \\
Cost of living & Healthcare & Private schools & Autotheft \\
Crimes & JobGrowthRate & Professional sports & Diversity index \\
Daily commute & JobRate & Restaurants & Growth \\
Democrats & Jobs & Transportation & Growth 2000 \\
Dinning & BlueCollar & Unemployment & Median rent \\
Recreation & & & \\
\hline
\end{tabular}

Bold indicates the variable that was selected in the analysis 
regional average. Tables, charts and graphs are created to illustrate the variation in performance between the various segments and to identify those segments that are potentially the most effective for marketing campaigns. One common method for demonstrating the variation between segments is a bar chart. A second more recent strategy for assessing performance is a cumulative lift chart (also referred to as a banana curve). Whether one uses tables, graphs or charts, comparisons are not statistically rigorous. Direct marketers who use test files of 100,000 or more records should, however, have faith that their results are stable.

\section{The Gini coefficient}

Social scientists use a statistical measure called the Gini coefficient to describe the disparity of a resource (eg income, race, wealth, education). Direct marketers have used the Gini coefficient to describe the distribution of customer spending. This paper posits that Gini can be used to describe the disparity of not only individual behaviours but also aggregations of consumers into consumer segments, and not only financial behaviours but also buying behaviours such as product purchases, response rates and inquiries rates. As a single number, Gini is easier to use when comparing different modelling methods or data files. Novak et al. ${ }^{23}$ state, 'The modified Lorenz (Gini coefficient)...should be considered if attention is to be directed specifically to the problem of reaching or capturing a fixed proportion of customers'. In addition, if the standard error of the Gini coefficient is known, one can make inferential assessments. ${ }^{24,25}$ When the standard error of Gini is not known, researchers have used bootstrapping techniques to estimate it. $^{26}$

Gini is defined as the measure of disparity within a population with respect to a resource (eg income). It can be used to compare distributions, assess model performance or validate the performance of a response model. It has been utilised in the direct marketing literature for these purposes. ${ }^{27-30}$ One shortcoming of the Gini coefficient is the absence of a method for calculating the standard error of Gini; recently, this has been of interest to economists. When the data points represent individual data points and are rank ordered according to the resource of interest, methods for computing the standard error of Gini are formulated. ${ }^{31-33}$ When Gini is formed from summarised data, however, the methods described by Giles and Oswang are inappropriate. One approach is to employ a jackknife sampling method to compute the standard error. ${ }^{34}$ The standard error of a Gini coefficient, developed from summarised data where the response variable is a dichotomous variable and where data records are ordered by predicted model scores and not response scores, can be approximated with the regression formula described by Greene and Milne. ${ }^{35}$ For the purpose of this paper a jackknife method is employed. This method assumes relatively large data files (greater than 5,000 records). The file used in case 2 falls short of the recommended file size.

\section{Data analysis}

\section{Case I: Upromise ${ }^{36}$ online shoppers}

Upromise, Inc. provided an analytic file of 10,474 online shoppers for this study. Upromise is a loyalty marketing company with over 9 million members. They partner with leading companies to create a rewards network for members. Whenever members purchase with Upromise partners, they receive a portion of their eligible spending back in the form of college savings. Upromise partners consist of both online and offline retailers, as well as consumer packaged goods companies. The analytic file includes customer spending in their first 12 months as well as a household-level segmentation system consisting of 70 unique segments. The data file was appended with an MSA-level exographic file of 33 variables (see Table 1). A total of 7,792 records were matched with MSA codes. A segmentation analysis was conducted that described average dollars spent by customers by household segment. A bar chart representing the differences between segments is shown in Figure 1. A cumulative lift chart is also presented to demonstrate the variation between segments (see Figure 2). 


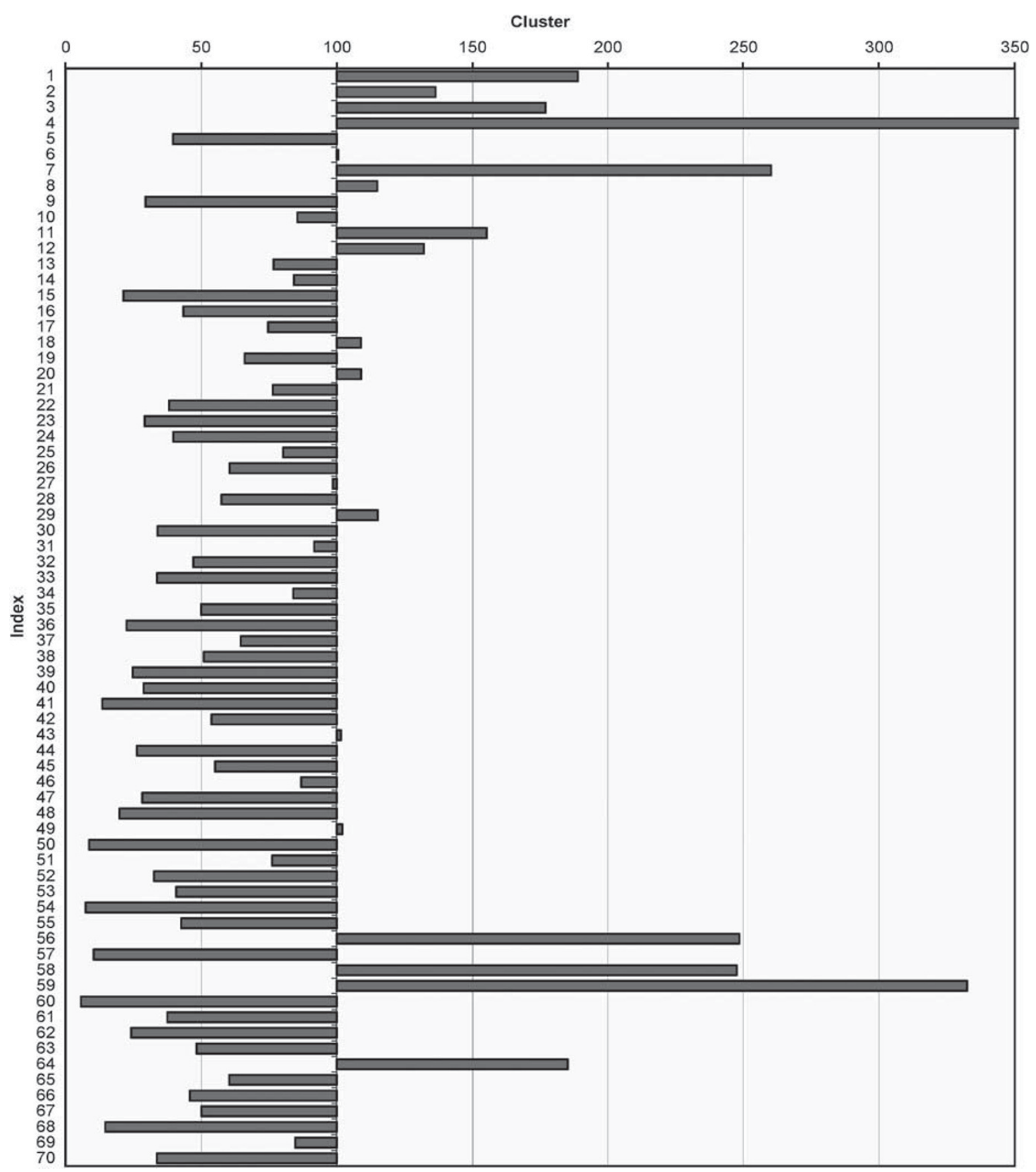

Figure 1: Case 1: Online shoppers segmentation analysis for household segments

A correlation analysis was conducted to determine which exographic variables were the best predictors of customer spending. The correlations of the best nine variables are presented in Table 2 .
Nine variables were identified as potential candidates. The variable with the highest correlation and that appeared logically intuitive was 'number of private schools'. The online marketing firm offers their members college 


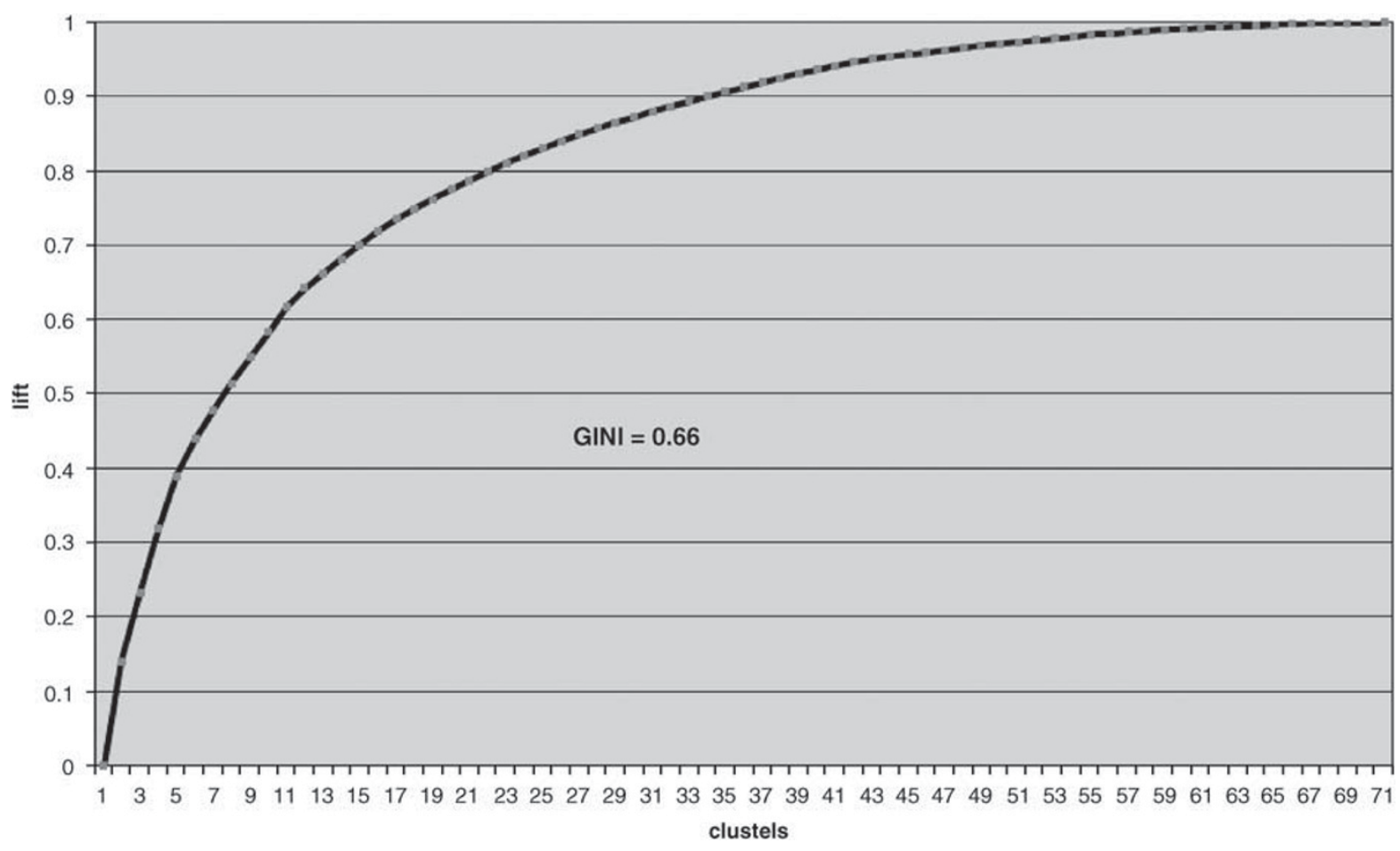

Figure 2: Case 1: Online shoppers cumulative lift chart for household segments

Table 2: Correlations of spending with best exographic variables

\begin{tabular}{llr}
\hline Exographics & Description & Correlations \\
\hline Collegetown & MSAs are rated by the number of colleges per person & 0.014 \\
Cost of Living & Cost of living for the MSA & -0.031 \\
Private school & The number of private schools in the area & 0.045 \\
JobGrowthRate & Change in the number of jobs in the market & -0.027 \\
JobRate & Employment rate & -0.027 \\
Growth & Population growth rate & 0.019 \\
Crimes & Number of crimes per person in the MSA & -0.025 \\
HazardousDays & Number of hazardous driving days & -0.015 \\
PrecipitationDays & Number of days with precipitation & 0.014 \\
\hline
\end{tabular}

Bold indicates the variable that was selected in the analysis

savings when they shop with selected merchants. Therefore, customers who live in areas surrounded by private schools and tuition fees would be more conscious of the need for saving for education. The private school variable was transformed into a binary variable, split according to the median number of schools. Each of the 70 household-level segments was split into two segments, one indicating a high number of private schools and one indicating a lower number of private schools. The same type of segmentation analysis conducted with the 70 segments was repeated with the 140 segments. Figure 3 illustrates the corresponding bar chart and Figure 4 exhibits the corresponding cumulative lift graph.

Comparing Figures 2 and 4, we see that the cumulative lift of augmented household segments is slightly better than the original household-level segmentation. Whether or not the difference is substantial cannot be determined simply by looking at the graphs. On the other hand, the bar charts show that spending indices created from the augmented segments far exceed the indices 


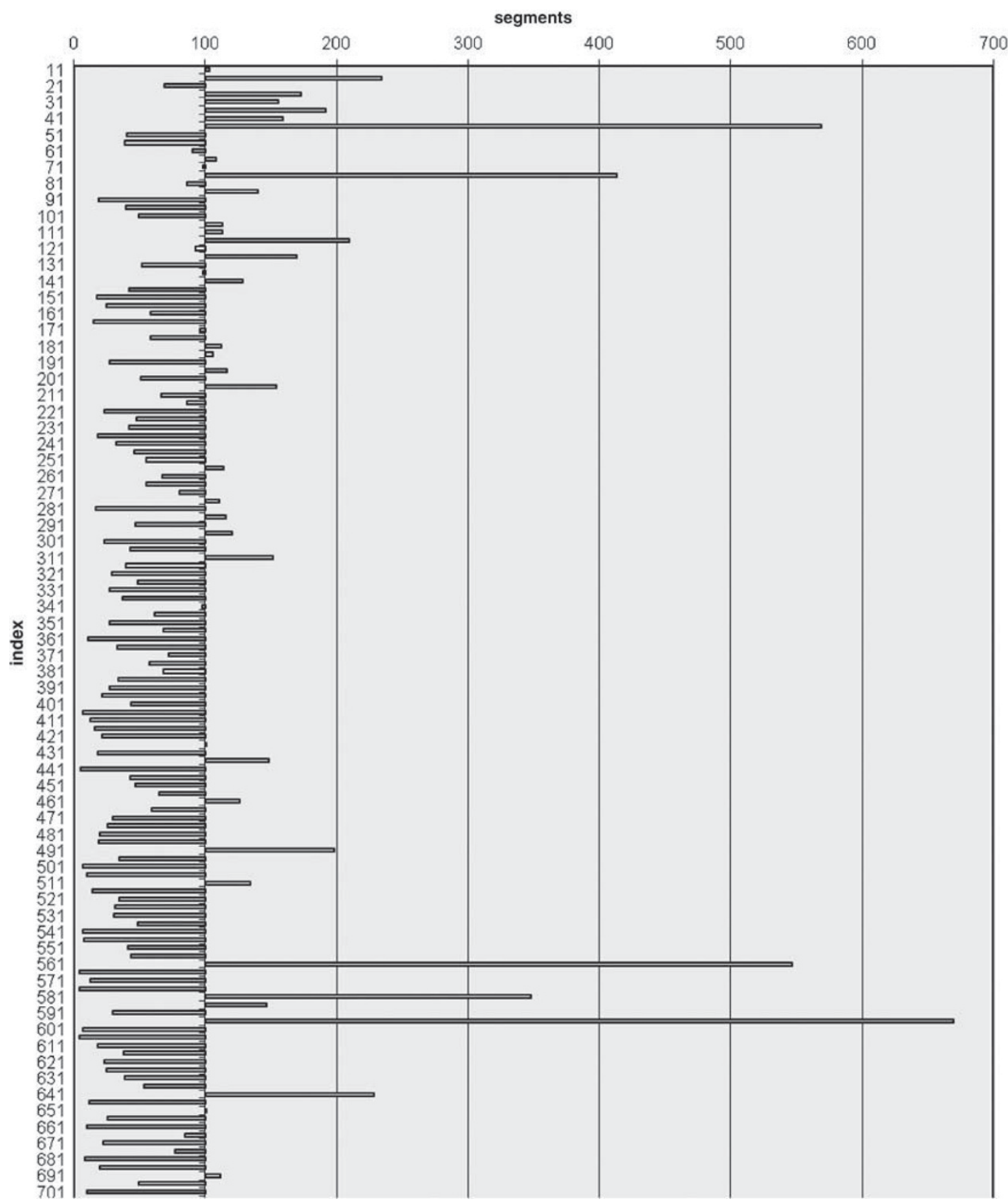

Figure 3: Case 1: Online shoppers augmented household segment analysis - binary split variable (private schools)

created from the household segments. Assuming the sample sizes are significant, this would indicate that there are some segments that can be targeted that will greatly outperform segments from the original household-level segmentation system. In fact, one of the augmented segments has an index 6.5 times greater than average, whereas, under the original analysis the best household segment is only 3.5 times better than average. Three segments have indices that are 5 times greater than average. If we describe the cumulative lift charts with the Gini coefficient, we see that the household segments have a Gini value of 0.66 and the augmented segments have a 


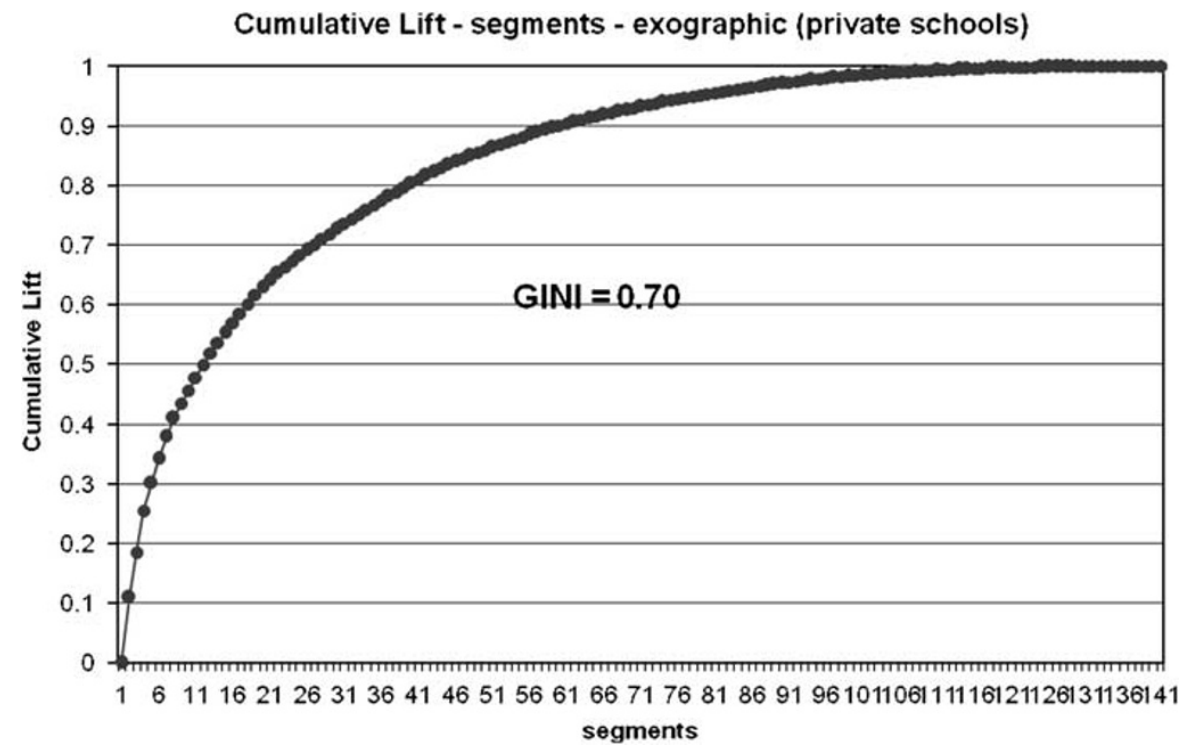

Figure 4: Cumulative lift chart for augmented household segments - binary split variable (private Schools)

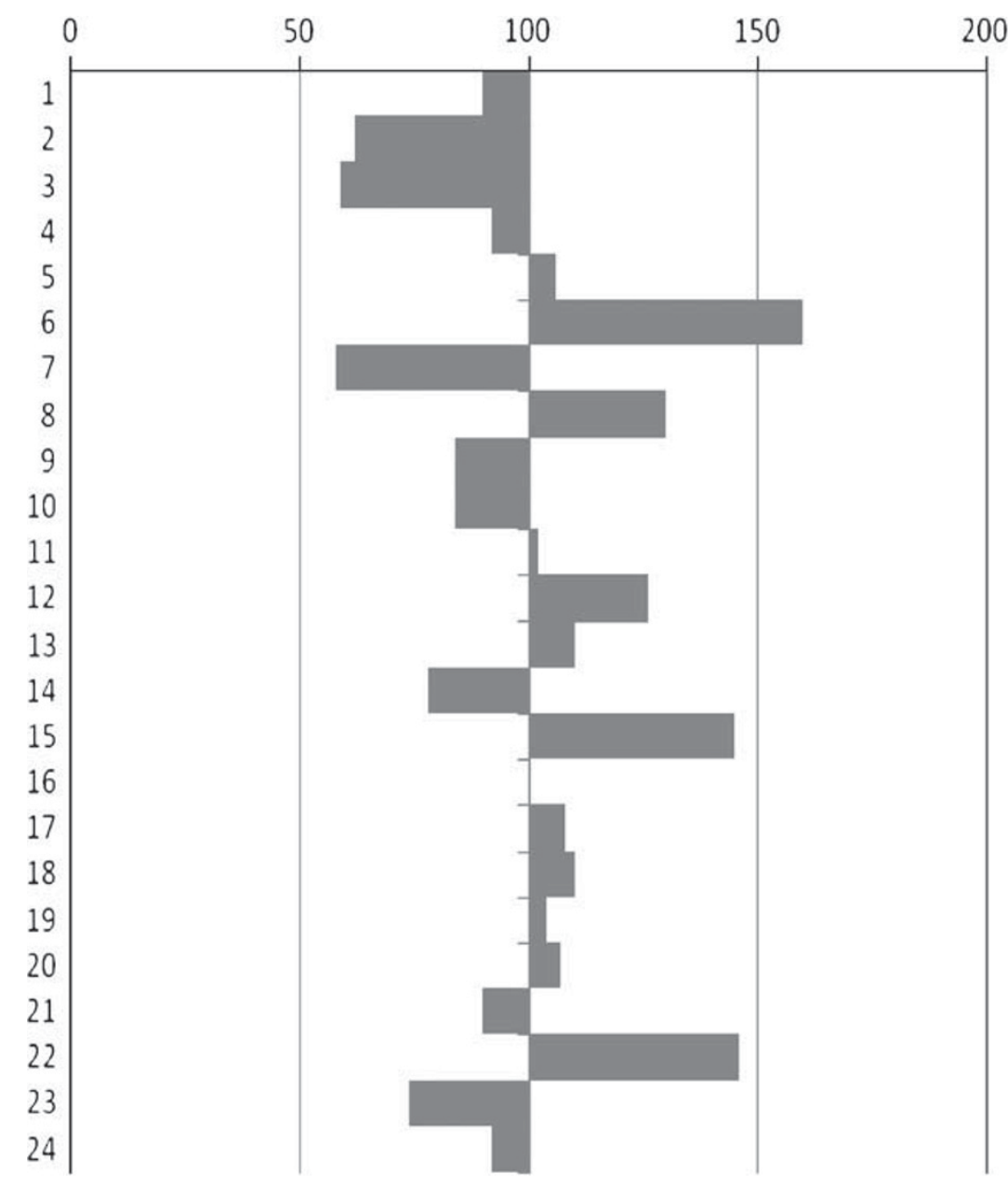

Figure 5: Case 2: Golf magazine subscribers - Segmentation analysis 
Gini value of 0.70 (a gain of 6 per cent).

Employing a jackknife method, we compute the standard error of Gini as 0.02. Assuming Gini is normally distributed, the augmented segmentation system would be 2 standard errors above the Gini for the original segmentation system, which is statistically significant $(p<0.02)$.

\section{Case 2: Golf magazine subscribers}

A file of 880 magazine subscribers was appended with 33 exographic variables, created at the MSA level. A segmentation analysis was created (national 24 cluster, geo-demographic segmentation system) to determine the best performing segments and to exhibit the variation in performance between segments (see Figure 5).

Three exographic variables were tested as possible candidates for augmenting the geodemographic segmentation system, climate, cost of living and golf courses per capita. For each exographic variable, a binary variable was created using a median split. Those MSAs that ranked below the median in terms of the exographic variable were labelled low and the other MSA geographies were labelled high. One variable, number of golf courses per capita, is presented (Figure 6).

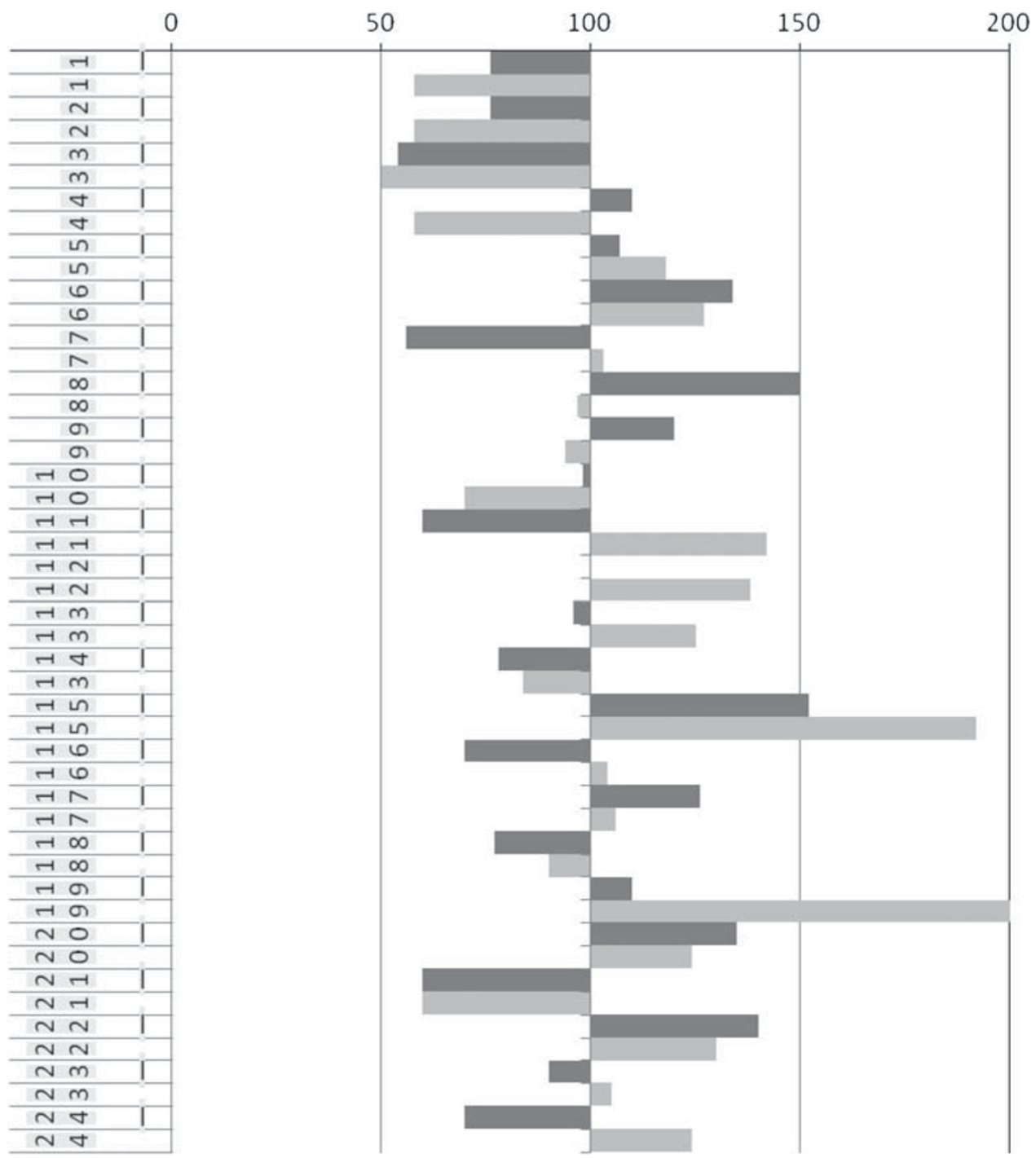

Figure 6: Case 2: Golf magazine subscriber segmentation analysis with binary split exographic variable. \#Golf courses per capita 


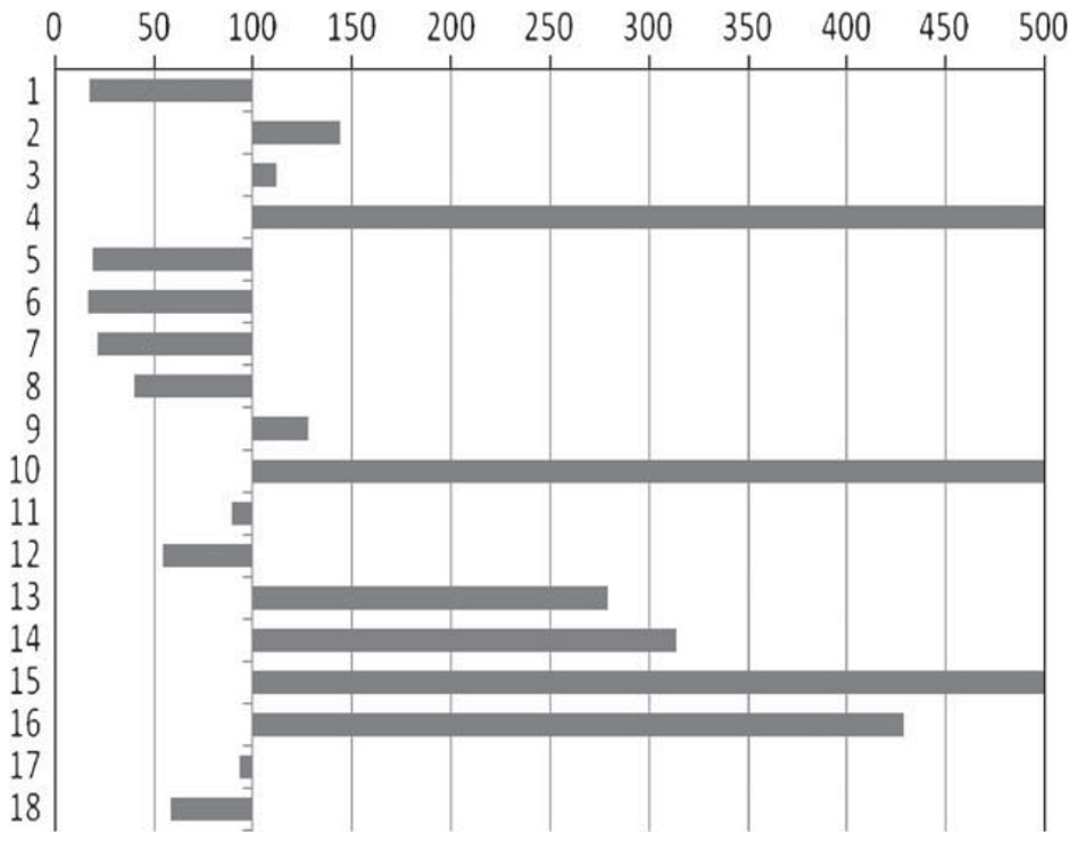

Figure 7: Case 2: Golf magazine exographic segmentation analysis - 18 segments (\# golf courses, cost of living and climate)

Based on the analysis, there are several market segments that will outperform the original segments. In this case, we are able to create two segments with indices of 180 and 200, whereas in the original segments, only one segment barely reached 150 . The Gini index for the original segmentation system is computed as 0.137 and for the augmented system 0.265 , a significant improvement. Out of curiosity, a segmentation system was created using only three MSA-level exographic variables (cost of living, climate and number of golf courses per capita). Golf courses per capita was created with a binary split as described previously and the other two variables were recoded with a trinary split (low, medium and high), creating $2 \times 3 \times 3=18$ possible segments. A segmentation analysis was created and the results appear in Figure 7.

The segmentation system built from only exographic variables produced extremely high indices for several segments. This example demonstrates the value of incorporating data elements relevant to the product or activity of interest.

\section{Case 3: Automobile insurance inquiries} In this case, 125,146 people who responded to a direct marketing advertisement regarding automobile insurance were contacted. The actual advertising campaign was mailed to over 4,000,000 households. The data file of responders was appended with a 24-cluster geodemographic segmentation system and an analysis was conducted to determine which type of segment was the highest responding (see Figure 8).

Figure 8 demonstrates that there are two specific segments that index higher than 150, and two other segments that index higher than 120 . These results are fairly typical of what can be achieved with a geodemographic segmentation system. One of the exographic variables tested was 'average travel time to work'. This variable was selected with the idea that areas in which people spend more time in cars would be congested, with more traffic, more accidents, more insurance payouts and higher premiums, causing the likelihood of people being in the market for automobile insurance to be higher. We used a median binary split on the variable travel time to work. Figure 9 represents the results.

In this case, there are three segments that index above 200, and 10 additional segments that index above 125 . This would prove to be a far superior tool for the insurance company. The Gini 


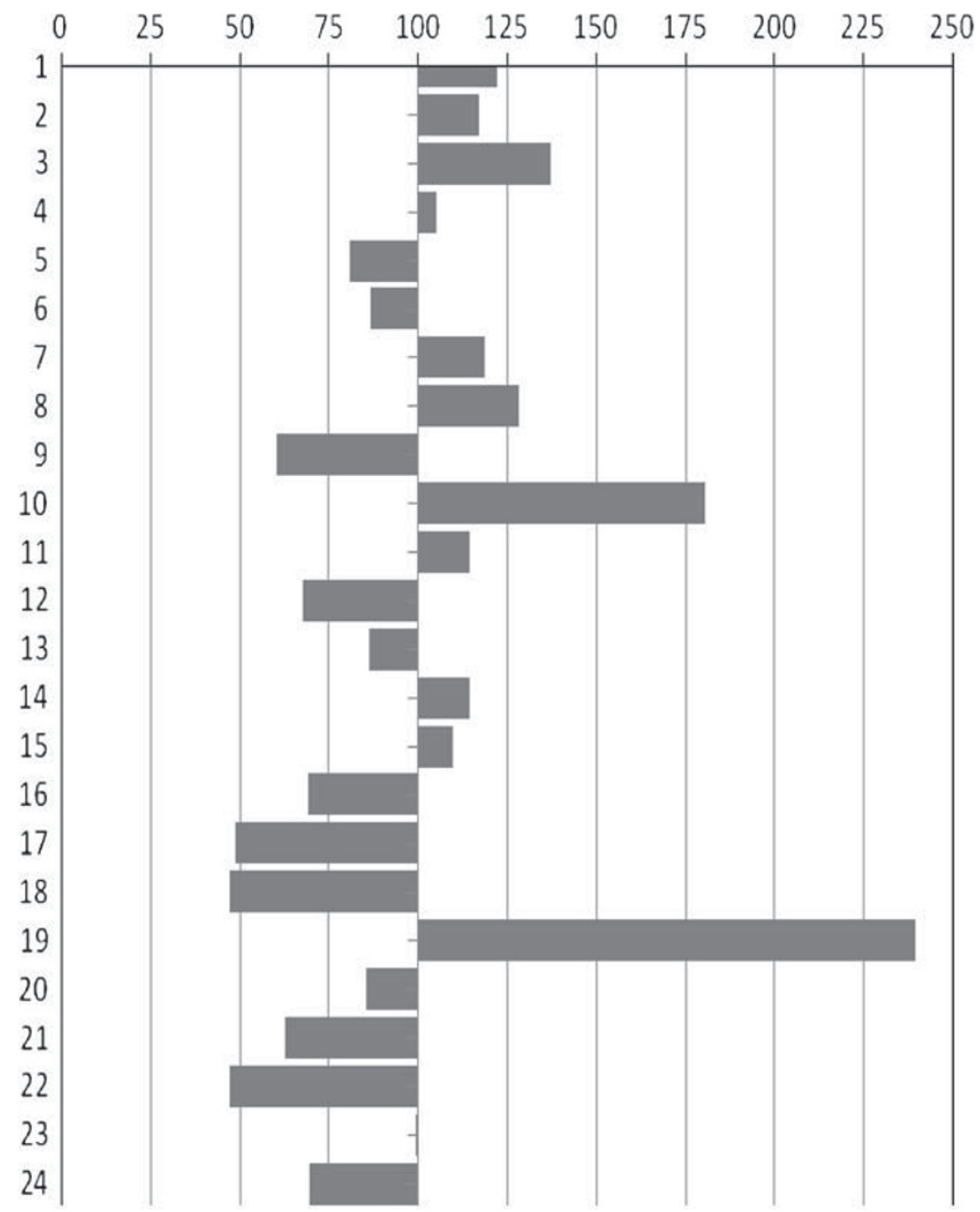

Figure 8: Case 3: Auto insurance responses segmentation analysis

associated with the original analysis is 0.225 , and with the binary split the associated Gini is 0.239 .

\section{DISCUSSION}

In Case 1, a standard household segmentation system was augmented with a binary exographic variable, subdividing the original 70 segments into 140 segments. We were able to demonstrate a significant gain in the Gini coefficient and, more importantly, we were able to create segments that greatly outperformed the segments in the original segmentation system. In the augmented system, three of the segments had indices between 550 and 650 , whereas in the original system, the maximum index was only 350 . The marketing consequence of targeting higher performing segments is the essential objective of all marketing analysis. In Cases 2 and 3, a generic geodemographic segmentation system was augmented with binary split exographic variables and again we were able to demonstrate for two different industry applications a substantial gain in targeting capability. In the second case, a segmentation system was built using only exographic variables and some of the segments had extremely high indices relative to the generic system. In each of the three cases, the Gini coefficients associated with the augmented systems were superior to the Gini coefficients associated with the original segmentation systems. 


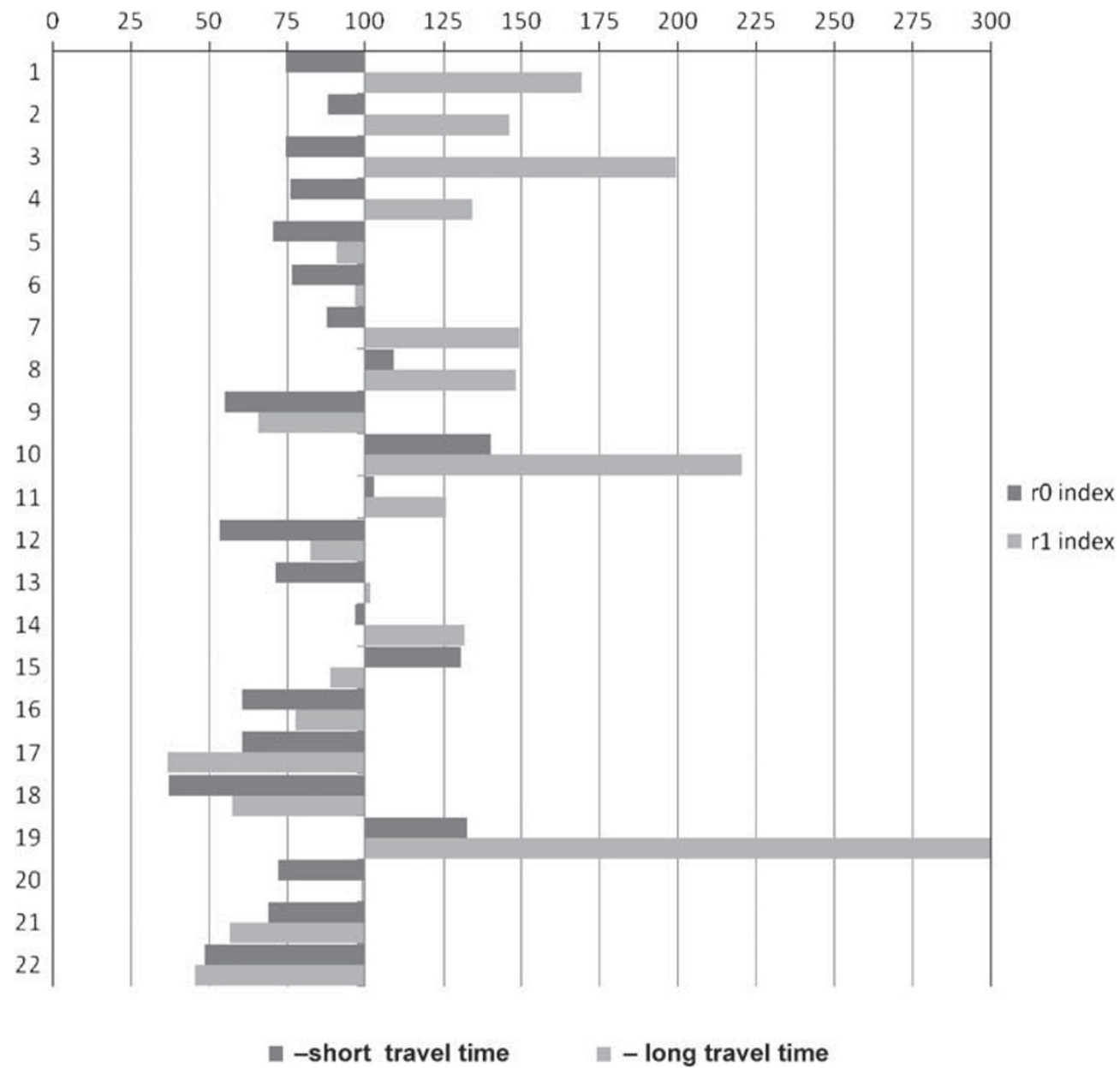

Figure 9: Case 3: Auto insurance responses segmentation and binary split analysis - travel time to work

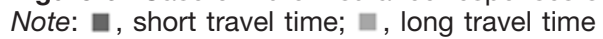

\section{CONCLUSIONS}

We demonstrated that by incorporating exographic variables into different segmentation systems, across different industries, significant model performance could be achieved, as measured by gains tables, cumulative lift charts and the Gini coefficient. It may be argued that this method of data augmentation might require additional investment in time and resources and may not be worth the net benefit. Although it is true that additional resources and expertise may be required, we do not believe that the additional effort would be a commercial impediment. Our augmentation procedure is both simple to understand and simple to implement.

We recommend that marketers consider augmenting segmentation systems with variables that correlate with the consumer behaviour of interest to improve segmentation performance, especially if the results of the analyses are meant to select target markets for advertising campaigns. The potential revenue gain is too great to ignore. Although we recommend exographics because they represent additional scales and data dimensions, other variables that are strongly correlated with the consumer behaviour of interest should also be considered. Consumers are influenced by an assortment of factors (cultural, social, personal, psychological, etc). Our ability to explain consumer behaviour with current data sources is weak at best. Therefore, improvement in performance should be tested by evaluating new data sources. Exographic variables appear to be worthy candidates for segment augmentation. 


\section{LIMITATIONS AND FUTURE INVESTIGATIONS}

This study consisted of three case studies in which one exographic variable was augmented to a segmentation system across three different industries. Additional exographic variables could have been added but by demonstrating the effectiveness of incorporating only one variable, we demonstrate the value of the strategy. This study did not test the method of augmenting with nonexographics, that is, other variable dimensions such as household-level demographics. It would be desirable to replicate the study with other variable dimensions and other consumer behaviours. We do not attempt to predict how much can be gained or what the financial impact might be, although this would be interesting to investigate. Our exographic data file is severely limited. We are strong believers in the value of this data concept and we encourage interested parties to join us in building more extensive data files.

\section{MANAGERIAL IMPLICATIONS}

Managers should note that it may be possible to simply and effectively enhance an off- the-shelf segmentation system by incorporating data items that represent alternative data dimensions that are logically appropriate for the consumer behaviour of interest and are statistically correlated. We expect that it is possible to increase response rates by at least 50 per cent among the best-targeted segments.

\section{References and Notes}

1 Cahill, D. (2006) 'Life Style Segmentation', The Haworth Press, New York.

2 Michman, R. (1991) 'Lifestyle Market Segmentation', Praeger, New York.

3 Weinstein, A. (1987) 'Market Segmentation', Probus Publications, Chicago.

4 Katzenstein, H. and Sachs, W. (1986) 'Direct Marketing', Charles E. Merrill Publishing Company, Columbus, $\mathrm{OH}$.

5 Wedel, M. and Kamakura, W. (2000) 'Market Segmentation: Conceptual and Methodological Foundations', 2nd edn, Kluwer Academic Publications, Norwell, MA.

6 Bickert, J. (1995) 'Focus on the Household', http://www. andreas.com/faq-geodemo4.html.

7 Baas, F., Tiger, D. and Londsdale, R. (1968) 'Market segmentation: Group versus individual behavior', Journal of Marketing Research, Vol. V, pp. 264-270.

8 Buchanan, B. and Morrison, D. (1987) 'Are direct marketers really $98 \%$ wrong', Paper presented at the ORSA/TMS Joint National Meeting, St Louis, October 25-28.
9 Greene, H. (2005) 'A statistic for measuring response model performance: Determining the significance of the gains chart', Dissertation, University of Massachusetts.

10 Greene, H. and Milne, G. R. (2005) 'Alternative data sources in targeted marketing: The value of exographics', Journal of Targeting, Measurement and Analysis for Marketing, Vol. 14, No. 1, pp. 33-46.

11 Lemmons, A. and Croux, C. (2006) 'Bagging and boosting classification trees to predict churn', Journal of Marketing Research, Vol. 43 (May), pp. 276-286.

12 Malthouse, E. (2001) 'Assessing the performance of direct marketing scoring models', Journal of Interactive Marketing, Vol. 15, No. 1, pp. 49-62.

13 Novak, T., de Leeuw, J. and MacEvoy, B. (1992) 'Richness curves for evaluating market segmentation', Journal of Market Research, Vol. 29, No. 2, pp. 254.

14 Schmittlin, D. (1986) 'Issues in measuring market concentration among firms, suppliers and customers', Working paper, University of Pennsylvania.

15 Schmittlin, D., Cooper, L. and Morrison, D. (1990) 'Truth in concentration in the land of 80/20 laws', Working paper UCLA.

16 Kotler, P. and Anderson, G. (2005) 'Principles of Marketing', 11 th edn, Prentice-Hall, New Jersey.

17 Goss, J. (1995) 'We know who you are and we know where you live: The instrumental rationality of geodemographic systems', Economic Geography, Vol. 71, No. 2, pp. 171.

18 Bickert, J. (1997) 'Cohorts II: A new approach to market segmentation', Journal of Consumer Marketing, Vol. 14, No. 5, pp. 362-379.

19 Mitchell, S. (1995) 'When clusters get personal', American Demographics, Vol. 17, No. 2, pp. 42-43.

20 Miller, B. (1995) 'A beginners guide to demographics', Marketing Tools, Vol. 2, No. 7, pp. 54-59.

21 Greene and Milne, ibid. 10

22 Savageau, D. (2000) 'Places Rated Almanac (Special Millennium Edition)', IDG Books Worldwide, Foster City, CA.

23 Novak et al., ibid. 13.

24 Greene, ibid. 9.

25 Greene and Milne, ibid. 10.

26 Lemmons and Croux, ibid. 11.

27 Kotler and Anderson, ibid. 16.

28 Greene and Milne, ibid. 10.

29 Mulhern, F. (1999) 'Customer profitability analysis: Measurement, concentration, and research directions', Journal of Interactive Marketing, Vol. 13, No. 10, pp. 25-40.

30 Malthouse, ibid. 12.

31 Giles, D. (2002) 'Calculating a standard error for the Gini coefficient: Some further results', Working paper EW PO202, Department of Economics, University of Victoria.

32 Ogwang, T. (2000) 'A convenient method of computing the Gini index and its standard error', Oxford Bulletin of Economics and Statistics, Vol. 26, pp. 123-129.

33 Ogwang, T. (2004) 'Calculating a standard error for the Gini coefficient: Some further results: Reply', Oxford Bulletin of Economics and Statistics, Vol. 66, No. 3, pp. 435-437.

34 Shlomo, Y. (1991) 'Calculating Jackknife variance estimators for parameters of the Gini method', Journal of Business and Economic Statistics, Vol. 9, No. 2, pp. 235-239.

35 Greene and Milne, ibid. 10.

36 Upromise is a registered service mark of Upromise, Inc. Information was provided for educational purposes only. 